\title{
Health insurance and switching behavior: Evidence from the Netherlands
}

\author{
Ferdy van Beest ${ }^{1}$, Christiaan Lako ${ }^{2 *}$, Esther-Mirjam Sent ${ }^{2}$ \\ ${ }^{1}$ Nyenrode Business University, Breukelen, The Netherlands \\ ${ }^{2}$ Radboud University Nijmegen, Nijmegen, The Netherlands; ${ }^{*}$ Corresponding Author: C.Lako@fm.ru.nl
}

Received 16 August 2012; revised 15 September 2012; accepted 29 September 2012

\begin{abstract}
Introduction: Since the introduction of the Health Insurance Act in the Netherlands in 2006, insurers are incentivized to compete on prices for basic health insurance, and on price and quality for supplementary insurance. The new health insurance system aimed to create a more competitive market in which consumers would switch health plans, thereby stimulating insurers to price competition and quality improvement. This article evaluates the switching behavior of Dutch consumers and evaluates whether this behavior is advantageous to the goals of the reform. Methods: Three surveys were conducted: from 20052006 ( $n=478), 2008-2009(n=389)$, and 20102011 (n = 191). Results: In 2005-2006, almost 20 percent of the Dutch consumers switched their insurance company. In between 2006 and 2012, however, the percentage of switchers decreased to less than four percent. The main cause of this decrease is that consumers no longer perceive sufficient differences between insurance companies in terms of premium and service. In addition, consumers have difficulties finding the proper information making the right decision and believe they may not be accepted for the supplementary insurance. Consequently, insurance companies only perceive limited incentives to create a more competitive market. Conclusion: Clear and unambiguous information, combined with an obligatory acceptance for the supplementary insurance might help to improve the potential mobility of Dutch consumers.
\end{abstract}

Keywords: Health Insurance; Switching; Survey

\section{INTRODUCTION}

Prior to the 2006 reform the Netherlands had a complex, mixed public and private health insurance system with a major role for public financing and a broad respect for the private provision of health care. This system was the result of several decades of incremental reform, legislated and implemented by various governments. While it was a fragmented and confusing system, nearly everyone had health insurance one way or another. About 65 percent of the population with incomes below a certain level (32,600 euros in 2004) had compulsory health insurance from one of the Sickness Funds and were automatically insured. This program was funded by general taxation (24\%), by income-related contributions subsidized by employers (66\%), and by community-rated individual premiums (10\%) [1].

In 2006, the three-tiered mix of public and private health insurance in the Netherlands was gradually replaced by a new, more competitive health insurance system as covered in the Health Insurance Act (HIA). The HIA was preceded by a series of more market-oriented reforms since the early 1990s [2]. It was a response to health care costs that had risen sharply and to a growing dissatisfaction with the existence of two parallel health insurance systems. It was considered unfair that each of these systems had a different set of rules [1].

The Netherlands, like many OECD countries, combine a mandatory basic health insurance with a voluntary supplementary health insurance [2]. In the HIA, the government no longer sponsors health insurance. In the new system, consumers are considered as rational individuals choosing health insurance wisely and willing to switch plans if dissatisfied. Health insurers compete on prices for the basic health insurance policy. The basic insurance packages are comparable, there is universal access, acceptance by insurance providers is mandatory, and the market could be considered as one with managed competition. In addition, supplementary insurances were provided to consumers differing on both costs and quality. The supplementary packages are voluntary to consumers, but there is no obligatory acceptance by the insurance company, and companies are allowed to use medical underwriting. The basic and supplementary insurance are (basically) always provided by the same health insurer. 
One important incentive for insurance companies to compete on price and quality draws upon consumer switching behavior. In 2006, the overall switching rate was about 20 percent. After 2006, the percentage of consumers switching their health insurance policy dramatically decreases to about four percent in 2009 [3]. Health insurers are no longer required to contract with all providers but they are rather encouraged to choose on the basis of negotiated arrangements with the providers they determine to be the best [1]. If consumers do not consider their health insurers as contractors of health care, the health insurers may not be encouraged to negotiate the best arrangements.

The aim of this study is to evaluate the HIA from 2006 onwards, with a focus on consumer switching behavior in particular. Therefore, we complement the study of Roos and Schut [2] in two particular ways. First, Roos and Schut focus on spillover effects, mostly from an insurance company perspective, whereas we review the health insurance market from a consumer perspective, with an in depth analysis of switching behavior. Second, in our analysis, we also consider the role of group purchases, since over 60 percent of Dutch citizens is a member of a group purchase agreement.

For this purpose, we describe switching behavior among Dutch consumers during the last few years. The measurement and evaluation of the switching behavior among the Dutch consumers is preceded by a description of the premises underlying the HIA. In particular, it is presumed that consumers are able to gather all relevant information and consequently that they are able to use this information properly in their decision making process. We evaluate whether these conditions were fulfilled. Furthermore, we study the varying factors related to switching plans in the period from 2006 to 2011. Finally, this study provides insights into reasons why, or why not, Dutch consumers switch their health care insurance.

The structure of this paper is as follows. In the following section, background information regarding the Dutch health insurance system is provided followed by the etiology of this system. After a description of the design of the methods and data we present the results on switching in. The final section provides a conclusion and discussion.

\subsection{Dutch Health Insurance}

As of January 1st, 2006, the Dutch Administration introduced the HIA, a system of more regulated competetion with a mandate for individuals to purchase insurance. The HIA was the final step of market-orientation that was gradually implemented from the beginning of the 1990s [2,4,5]. The new system created competition in three areas. First, health insurers function as contractors of health care. They are no longer required to contract with all providers of health care but they are rather encouraged to choose on the basis of negotiated arrangements resulting in the lowest cost and best quality. Secondly, competition was created by the introduction of Diagnosis Related Groups in hospital care [6]. And third, competition was created in the health insurance market between consumers and insurance companies, as Dutch consumers are allowed to switch their insurance company (or insurance package) each year. This article evaluates the functioning of the third market in which consumers have a free choice between insurance companies during annual enrolment (November-January).

The aim of this system is to create a competitive market in which consumers would switch health plans and stimulate insurers to price competition and quality improvement. The standardized basic insurance is fairly comprehensive and obligatory for all Dutch citizens. The universal package covers, amongst others, hospitalization, prescription drugs, and maternity care [2].

Health insurers are required to accept all applicants for the basic insurance [7]. In addition to the basic insurance, Dutch consumers are allowed to voluntarily buy a supplementary policy covering care from, for instance, dentists, opticians, and physiotherapists. However, for the supplementary insurance, insurers are no longer required to accept these consumers and may require medical underwriting before acceptance.

The literature suggests that individuals switch when they are confronted with cheaper health plans [8], but the difference in prices should be worth the trouble of switching in terms of time and administrative hassle. Crucial are therefore differences in price, for the basic health insurance policy in particular, since these pack- ages are comparable. Because the basic insurance holds a universal and obligatory acceptance by all insurance companies, consumers are free to choose their company. Small differences might not result in substantial improvements in the efficiency of health care. However, Roos and Schut [2] show that about $90 \%$ of the Dutch citizens also have a supplementary insurance that may have restrictions on acceptance by the insurance company. Due to the differences in supplementary packages, combined with potential rejection and potential age discrimination, availability, quality and, and price of the supplementary policy are considered important for consumers in deciding whether to switch. And despite the fact that the basic and supplementary policies are autonomous by law, most Dutch people perceive their insurance as one product and think that they have an obligation to buy the basic and supplementary insurance from one company (approximately 60 percent in our survey).

\subsection{Etiology of Health Plan Switching}

The literature suggests that several factors are involved in 
the process of health plan switching. Although basic insurance packages are comparable, health plans are not considered as homogeneous products in the Netherlands [9]. This is because over 90 percent of Dutch consumers have a supplementary insurance [2] that deviates among insurance providers and the basic and supplementary insurance are assumed to being bought from one company. This would be an argument to include information related to both price and quality of insurance products in switching studies.

Price is generally considered an important factor [10]. A study in the US shows that price increases generally increase switching [11]. On the other hand, price does not always determine switching behavior [12]. The low percentage of switching can also be explained by the status quo bias; tendency of people to leave things as they are [13]. Switching may in some cases be the result of calculated anticipation of specific needs for medical care. Specifically when insurance companies use medical underwriting, or consumers are afraid of not being accepted by a new insurance company, consumers may not be able to attract a better supplementary contract. This is the so called lock-in effect [2]. Dormont et al. [14] have shown this effect using data from Switzerland, which has a system that is fairly comparable to the Dutch HIA.

Another argument to switch from insurance company is the opportunity to join a purchasing group. Collective offers from purchasing groups have been shown to be one of the main arguments to switch, although it is not clear why consumers join these groups. Lower premiums might be a reason, but higher quality of the insurance product [15] as well. As a result, switching always seems voluntary, but when consumers are enrolled in a collective offer via their employer and change careers, they have an obligatory reason to switch their insurance product.

Furthermore, (perceived) availability is important to consider when studying switching behavior. Switching, for instance, is not without transaction costs. Searching involves time and the question is whether consumers will actually be accepted for the supplementary policy or need to fill in a medical underwriting [2]. This may have a discouraging effect. Moreover, too much choice [16] might keep consumers from switching at all. Roos and Schut [2] show that about 30 insurance companies provide supplementary insurance, with many different packages per company. Quality of information plays a role here, because one could question whether consumers are able to compare all different insurance plans. Quality of information has been shown to have a small effect on switching [15], but other studies do not confirm this outcome [17].

In addition, studies into health status reveal that healthy individuals tend to switch more than those who are sick
[9]. The same applies for well-educated individuals compared to lower educated individuals [9]. Finally, when we look at socio-demographic variables, we see the following outcomes: younger people tend to switch more than elderly people, but for gender and living status the literature mentions varying relationships with switching behavior [9].

\section{METHOD}

We employed three surveys to obtain in depth insight into consumer switching behavior, but also why consumers seem to neglect the opportunities to switch health insurance in more recent years. The first two surveys were completed in cooperation with radio Noorderlicht, the latter in cooperation with its successor, i.e. Labyrint radio. All three programs cover scientific news. And as such, on average, our respondents are more highly educated compared to the average Dutch population. However, as Hurenkamp and Kramer [18] show, highly educated people are better able to deal with rational decision problems. Therefore, when we find that this group encounters difficulties in finding the right information, and making the right decision, this result will be even worse for the entire Dutch population. We will consider this bias when discussing the results.

The first survey aims at creating a deeper understanding of health insurance switching in the Netherlands during the introduction of the HIA in 2006. Respondents were allowed to complete the survey between the 6th and 19th of March 2007 on the radio’s website (http://noorderlicht.vpro.nl). The survey was completed by 478 respondents. Over thirty-five percent was female. The average time to complete the survey was approximately three minutes.

The 2005-2006 survey primarily aimed to develop insight into people's switching behavior. Respondents were asked: "did you recently switch to another health plan?" (Yes/No). After this question we were particularly interested in finding out why consumers switched their health insurance. They were queried about the reasons for doing so (premium, group purchasing plans etc.). Moreover, information about socio-demographic variables was included in the questionnaire, including age, gender, and education level. Along the lines of previous studies (e.g. [19]) we included the following variables in our survey: premium per month, membership of a purchasing plan, expectations about improved service, and dissatisfaction with the previous health insurance company. The variables were measured on a 5-point scale from 1 (hardly) to 5 (very much) in order to create a hierarchy among these determinants.

The 2009 survey was completed by 389 respondents. This survey focuses on health plan switching in November 2008-January 2009. The primary aim of this survey 
was to find out why relatively few consumers actually switch their insurance plan. This question gained importance as the percentage of consumers switching health plans dramatically decreases from 20 percent in 2006 to four percent in 2009 [3]. Additionally, this latter questionnaire distinguishes between non-switchers not having considered changing their health care insurance and nonswitchers that did re-evaluate their opportunities, but in the end deliberately decided not to switch their insurance plans [7]. Respondents were allowed to fill in this survey in April 2009. The final survey $(n=190)$ was available in February 2011 for respondents to fill in. This was a relatively small survey, used to gain some extra insight into non-switching behavior, for instance related to the expectation of not being accepted [2] and the opportunity to find the right insurance. All surveys were designed to include respondents with a health insurance. These are Dutch people aged 18 years and older as children have free insurance with their parents. A paired samples t-test was used to uncover differences between groups. In addition, Anova testing was used.

\section{RESULTS}

After the introduction of the HIA in 2006, 31.6 percent of the survey respondents changed their health plan. In the Netherlands as a whole this was almost 20 percent. Similarly, our results show that over ten percent of our respondents switched their health plans in 2009 and 2011, whereas this was about four to five percent in the entire country. Table 1 displays a description of the respondents in the three surveys.

The average age of our respondents was 46.1 (20052006), 46.3 (2008-2009) and 49.2 years, respectively. Age is normally distributed. The level of education is relatively high. In the Netherlands as a whole, the percentage of people holding a higher education or university degree is approximately 28 percent [20]. The difference between the percentages can be explained by the sampling method, as discussed in the previous section. Radio Noorderlicht and Labyrint radio primarily focus on scientific novelties. As a result, the average listener to this program is more highly educated. However, individuals with higher levels of education have been shown to search more

Table 1. Respondent characteristics.

\begin{tabular}{cccc}
\hline & $\begin{array}{c}2005-2006 \\
(\mathrm{n}=478)\end{array}$ & $\begin{array}{c}2008-2009 \\
(\mathrm{n}=389)\end{array}$ & $\begin{array}{c}2010-2011 \\
(\mathrm{n}=190)\end{array}$ \\
\cline { 2 - 4 } Switched & $31.6 \%$ & $10.2 \%$ & $14.0 \%$ \\
Male & $64.4 \%$ & $60.7 \%$ & $66.4 \%$ \\
Female & $35.6 \%$ & $39.3 \%$ & $33.6 \%$ \\
Age & $46.1(\mathrm{sd} .=13.9)$ & $46.3(\mathrm{sd} .=14.7)$ & $49.2(\mathrm{sd} .=17.4)$ \\
Higher education & $78.7 \%$ & $74.8 \%$ & $74.3 \%$ \\
\hline
\end{tabular}

often for information and are better able to compare this information [18]. Hence, whenever the results would indicate that even this group of highly educated consumers has problems finding or comparing the information on health plans, the results will even be worse for lower educated consumers. No structural biases were found between the three surveys, using Anova testing (not in table).

\subsection{Switching in 2006}

The new health care system created a relatively high mobility of consumers switching in the first year. In our sample, 31.6 percent deliberately chose a different health plan, considerably more than in the whole Dutch population (20\%). The same question was asked in the 20082009 survey. Table 2 shows that over 10 percent of our respondents changed their health care insurance plan in 2008-2009. This percentage is higher than the countries' average of approximately four percent [3], but lower than the percentage of 2005-2006. The switching behavior and the independent variables in this study are presented in Table 2. Table 3 compares the outcomes on the independent variables from the first two surveys, using a paired samples t-test. We start with discussing the average results of 2005-2006 as presented in Table 2. Results can ultimately deviate between 1 (hardly) to 5 (very much), using a five points Likert scale.

Table 2. Factors explaining switching health plans: Average and standard deviation.

\begin{tabular}{lcc}
\hline & \multicolumn{2}{c}{ 2005-2006 $(\mathrm{n}=478)$ 2008-2009 $(\mathrm{n}=389)$} \\
\cline { 2 - 3 } $\begin{array}{l}\text { Percentage of switching } \\
\text { consumers }\end{array}$ & 31.5 & 10.2 \\
Monthly premium & $3.70(1.40)$ & $3.57(1.65)$ \\
$\begin{array}{l}\text { Membership of a purchasing } \\
\text { group }\end{array}$ & $3.46(1.65)$ & $2.05(1.62)$ \\
$\begin{array}{l}\text { Service } \\
\text { Dissatisfaction with previous }\end{array}$ & $2.77(1.42)$ & $2.80(1.52)$ \\
insurance company & $2.04(1.37)$ & $2.43(1.39)$ \\
\hline
\end{tabular}

Table 3. Factors explaining switching health plans (Paired samples t-test, p-values).

\begin{tabular}{|c|c|c|}
\hline & 2005-2006 & 2008-2009 \\
\hline $\begin{array}{l}\text { Monthly premium versus membership } \\
\text { of a purchasing group }\end{array}$ & 0.155 & $0.001^{* *}$ \\
\hline Monthly premium versus service & $0.000^{* *}$ & $0.023^{*}$ \\
\hline $\begin{array}{l}\text { Monthly premium versus dissatisfaction } \\
\text { with previous insurance company }\end{array}$ & $0.000^{* * *}$ & $0.002^{* *}$ \\
\hline $\begin{array}{l}\text { Membership of a purchasing group } \\
\text { versus service }\end{array}$ & $0.000^{* *}$ & 0.061 \\
\hline $\begin{array}{l}\text { Membership of a purchasing group } \\
\text { versus dissatisfaction with previous } \\
\text { insurance company }\end{array}$ & $0.000^{* *}$ & 0.319 \\
\hline $\begin{array}{l}\text { Service versus dissatisfaction with } \\
\text { previous insurance company }\end{array}$ & $0.000^{* *}$ & $0.020^{*}$ \\
\hline
\end{tabular}

${ }^{*}$ significant at $5 \% ;{ }^{* *}$ significant at $1 \%$. 
The first item, monthly premium, refers to monthly payments and whether consumers received a cheaper opportunity for their health care insurance. The question is whether this stimulated consumers to switch their health insurance. With an average of 3.70 and a standard deviation of 1.40 this item clearly contributed to explaining switching behavior. Purchasing group, service, and dissatisfaction towards the former insurance company scored 3.46, 2.77 and 2.04, respectively. This means that on average the monthly premium was most important for the decision to switch, followed by membership of a purchasing group, service, and dissatisfaction towards the former insurance company.

To verify whether the measured differences are significant, we used a paired sample t-test (Table 3). Despite the mean difference of 0.24 , the results between monthly premium and membership of a purchasing group do not differ significantly for 2005-2006 when explaining switching behavior $(\mathrm{p}=0.155)$. On the other hand, monthly premium and membership of a purchasing group are not associated significantly.

When reflecting on the other measured differences we see that results are significant at the $1 \%$ level (see Table 3). These results suggest that there was a relatively strong hierarchy among explanatory variables, in which good opportunities in terms of monthly premiums and/or group purchases induced consumers to switch more than the expectation to receive better service at this new firm. Dissatisfaction towards the former insurance company was the least explanatory factor.

In line with our expectations, consumers' sex does not have any influence on their switching behavior (not in table). Age has a negative coefficient, but the result is insignificant. Education also lacks significance. This result, however, may be due to our population, which is relatively homogeneous and on average highly educated.

\subsection{Developments between 2006 and $2009^{1}$}

Before we continue with the results from 2009, a concise reflection on the developments between 2006 and 2009 is necessary. One of the aims of establishing a more competitive health insurance market was to improve the efficiency and effectiveness of health care, which contributes to decreasing costs of the total health care system. For Dutch consumers, however, the costs of the new system increased significantly. In addition to the increased monthly premium, another policy change increased the costs for consumers. A co-payment was introduced in 2006. This co-payment implied that when consumers did not use service from the basic health care plans, they were reimbursed by the end of the year. It

\footnotetext{
${ }^{1}$ The reason to include the developments section here facilitates the
} transition from the 2006 to the 2009 results. appeared that the instrument did not reduce medical consumption. As a result, the co-payment was replaced by an obligatory "own risk", which implied that Dutch consumers have to pay themselves for their initial costs when basic health care is necessary [1], i.e. €220 for 2012.

In addition, the costs of health care in broad sense increased relatively strong. To restore premiums, and create economies of scale, mergers and acquisitions among insurance providers were necessary for becoming viable. In the end, however, only four big players were left covering over 80 percent of the total market. These big players subsequently restored their premiums, resulting in higher monthly premiums for Dutch consumers. In 2006 they had suffered a predictable loss of about 30 percent on the highest decile of health care users [2]. Moreover, there were fewer opportunities to choose from and it seems there was only limited competition. After 2006, the monthly premium strongly converged between insurance companies [21], especially for the basic insurance. Consequently, perceived differences were limited and the incentives for consumers to switch decreased. Moreover, when only a limited percentage of consumers switch health plans, there is only limited need for health insurance companies to actually engage in strong competition, leaving them with the opportunity to restore premiums.

Furthermore, over 60 percent of Dutch consumers is a member of a purchasing group. This enabled the creation of volume discounts. Consumers involved in a group purchase (mostly via their employer) therefore either received a discount on their monthly premiums, or gained additional coverage and service for the same price. The effect, however, is that they no longer actively search for better opportunities, whereas this is one of the assumptions of rational decision making and efficient market. Hence, one of the aims of the 2008-2009 survey was to study whether consumers decided not to switch their health insurance after active comparisons and careful deliberation, or whether consumers simply accepted the situation without any critical reflection.

\subsection{Results $2008-2009$}

It is interesting to investigate whether the reasons to switch health care insurance among respondents changed over the years. These results are included in Tables 2 and 3 . Table 2 enables us to assess how much each item contributes to consumers switching their health care insurance company. The first item (monthly premium), has an average score of 3.57 and a standard deviation of 1.56. In 2008-2009 this factor most prominently contributed to explaining switching behavior, which is comparable to 2005-2006. Membership of a purchasing group, on the other hand, strongly decreased between 2005-2006 and 2008-2009. The average score is 2.05 and the standard deviation is much less than the 3.46 of three years before. 
Service shows an average result of 2.80, whereas dissatisfaction towards former insurance provider results in an average score of 2.43 and a standard deviation of 1.39.

Results changed from 2006 to 2009 (see Table 3), creating a different hierarchy among explaining determinants. Monthly premium is still most important when explaining switching behavior. Significant results occur when comparing the mean average of monthly premiums with service (at the 5 percent level) and membership of a purchasing group and dissatisfaction towards former insurance company (at the 1 percent level). As a result, the relevance of purchasing groups in explaining the switching behavior decreased, since the measured difference in 2005-2006 was insignificantly different from monthly premium. This decreased relevance was also confirmed by the other results. In 2005-2006 membership of a purchasing group was significantly more important than service in explaining switching behavior (see Table 3 ). In 2008-2009, the average score of service is even higher than the result of purchasing groups (2.80 and 2.05 , respectively).

Three results about dissatisfaction with the previous insurance company are worth mentioning. First, a comparison of the primary results of 2005-2006 (mean $=2.04)$ and 2008-2009 (mean $=2.43$ ) suggests that this variable gained importance. The reasoning is as follows: as a result of earlier opportunities to switch their insurance plan, consumers indeed switched their insurance company. Sometimes, however, this behavior caused dissatisfaction due to postponed payment, complex request submission procedures, and worse customer service etc. Essentially, these consumers decided to switch back again to their previous insurance provider. A second interesting result, and similar to the comparison between purchasing group and service, is that membership of a purchasing group is no longer more important than dissatisfaction when explaining switching behavior ( $p=0.319$ ). Dissatisfaction even has a higher average score in the 2008-2009 measurement. Finally, perceived service is significantly more important than dissatisfaction at the 5 percent level.

As mentioned before, less than four percent [3] of Dutch consumers decided to switch their health insurance policy in 2008-2009. Hence, in addition to re-testing the 2005-2006 result, we included questions concerning the importance of certain factors explaining health care insurance plan selection. In this way we were able to further explore switching and non-switching behavior $(\mathrm{n}=$ 389). Results are displayed in Table 4.

When reflecting on monthly premium we find a significant difference between the perceived relevance of monthly premium when comparing switchers and nonswitchers $(p<0.01)$. This result is in line with our earlier findings, as monthly contribution remains the main argument to switch insurance policies (see Tables $\mathbf{2}$ and 3).
Table 4. Explanatory factors for choosing a insurance company: Averages and differences (2008-2009).

\begin{tabular}{cccc}
\hline & $\begin{array}{c}\text { Switchers } \\
(\mathrm{n}=40)\end{array}$ & $\begin{array}{c}\text { Non switchers } \\
(\mathrm{n}=349)\end{array}$ & $\begin{array}{c}\text { Significant } \\
\text { difference (p-values) }\end{array}$ \\
\cline { 2 - 4 } Monthly premium & 4.00 & 3.16 & $0.000^{* * *}$ \\
Trust & 3.67 & 3.56 & 0.595 \\
Convenience & 3.07 & 3.56 & $0.013^{*}$ \\
Service & 3.48 & 3.55 & 0.707 \\
\hline
\end{tabular}

"significant at $5 \%$; ${ }^{* *}$ significant at $1 \%$.

Furthermore, switchers and non-switchers do not differ significantly on trust and service. In other words, both the trust in the insurance company and perceived service are valued fairly similarly by switchers and non-switchers. Finally, however, we find a significant difference in perceived convenience. This result is significant at the $5 \%$ level. Non-switchers deliberately decide to stay with their insurance policy as a result of perceived convenience. Switchers, on the other hand, perceive a lower level of convenience. This triggers them to search for a better opportunity.

As mentioned before, the average percentage of switchers dramatically decreased throughout the years. The policy of the Dutch Administration, however, assumes that consumers acting as rational individuals [9] are at least willing to re-evaluate their health insurance decisions, whereas the convenience results suggest differently. Therefore, we subdivided the non-switchers into non-switchers not having considered changing their health care insurance, and non-switchers that re-evaluated their opportunities, but in the end deliberately decided not to switch their insurance plan [7]. An evaluation of both groups enables us to verify whether future incentives at this insurance market might be useful. The sample consists of 389 respondents, of whom 40 respondents switched their health care insurance. Out of the remaining 349 respondents, 112 respondents indicated having reconsidered whether or not to change their insurance plan. In other words, despite the ambitions of the Dutch Administration, 237 respondents (far over 50\%) do not even consider changing their health care insurance.

Hence, for the purpose of evaluating non-switching behavior we asked these 349 respondents why they did not change their health care insurance. Results are displayed in Table 5, measured on a 5-point Likert scale (1 = hardly to $5=$ very much). Although both groups decided not to switch their health care insurance, many significant differences occur. Starting with non-switchers that considered switching their insurance company we find three interesting results. First, and in line with our expectations, non-switchers that considered switching perceive too limited differences when comparing monthly premiums. Moreover, this group either finds insufficient information among good alternatives, or the information 
they found was too complex to make a well informed decision. These results are important and suggest that many people are willing to consider a switch, but are not able to make the right decision with the current information. This is in line with Roos and Schut [2] who also propose an improvement concerning information delivery. Essentially then, the relatively high costs of searching outweigh the potential benefits of good alternatives. A model based on the "virtual guardian angel" as suggested by Poiesz and Van Raaij [22] could contribute to this problem by introducing a helpdesk for consumers improving their health insurance.

An even larger group of respondents, however, does not even consider switching their health care insurance. This group is satisfied with current service of their insurance provider and monthly contribution they have to pay. Moreover, this group presumes that their purchasing group is simply the best alternative. Hence, as a result these consumers hardly search for better alternatives, which seems contradictory to the initial intentions of the government introducing the market-oriented health insurance system.

\subsection{Future Markets}

We now explore future opportunities for improving the health care insurance market. A necessary condition for competition among insurance companies is sufficient switching behavior among Dutch consumers. A lack of mobility would result in a limited incentive for insurance providers to develop distinguishing characteristics, inter alia related to monthly premiums and provided service. Hence, Table 6 displays the arguments that might contribute to more switching behavior. In other words, this table shows what changes are necessary to increase the mobility of Dutch consumers in the health care insurance market. We again subdivided the non-switchers into two groups: non-switchers not having considered changing their health care insurance and non-switchers that did consider changing their health care insurance. Results are measured on a 5 -point Likert scale $(1=$ hardly to $5=$ very much).

Table 6 shows that monthly premium, service, and dissatisfaction towards insurance provider are decisive for future switching behavior. This result concerns both groups. Most striking in Table 6, however, are the main differences between both groups. The differences on all items are significant (either at the 1, or 5 percent level). These results suggest that the first group indeed considered switching their insurance company; however, the perceived differences were not persuasive enough to actually change their insurance plan. The latter group seems relatively indifferent; even though differences would be significant, it remains unlikely that this group will actually change their health care insurance.

Table 5. Reasons for not switching health care insurance (2008-2009).

\begin{tabular}{|c|c|c|c|}
\hline & $\begin{array}{l}\text { Non-switchers; switching } \\
\text { considered } \\
(\mathrm{n}=112)\end{array}$ & $\begin{array}{c}\text { Non-switchers; switching } \\
\text { not considered } \\
(\mathrm{n}=237)\end{array}$ & $\begin{array}{c}\text { Significant difference } \\
\text { (p-values) }\end{array}$ \\
\hline Insufficient differences on premium & 3.45 & 2.71 & $0.000^{* *}$ \\
\hline Satisfied with service current insurance provider & 3.32 & 3.90 & $0.000^{* *}$ \\
\hline Lacking opportunities for membership of a purchasing group & 2.25 & 2.08 & 0.273 \\
\hline Information about alternatives was too complex & 3.43 & 2.77 & $0.000^{* *}$ \\
\hline Purchasing group was already considered as the best alternative & 2.19 & 2.83 & $0.000^{* *}$ \\
\hline Satisfied with current monthly premium & 2.88 & 3.19 & $0.001^{* *}$ \\
\hline
\end{tabular}

*significant at $5 \% ;{ }^{* *}$ significant at $1 \%$.

Table 6. Future arguments to switch health care insurance (2008-2009).

\begin{tabular}{lccc}
\hline & $\begin{array}{c}\text { Non-switchers; switching considered } \\
(\mathrm{n}=112)\end{array}$ & $\begin{array}{c}\text { Non-switchers; switching not considered Significant difference } \\
(\mathrm{n}=237)\end{array}$ & \begin{tabular}{c} 
(p-values) \\
\cline { 2 - 3 } Larger differences in monthly premiums
\end{tabular} \\
\cline { 2 - 4 } Larger differences in service & 4.19 & 3.63 & $0.000^{* *}$ \\
More opportunities for purchasing groups & 4.09 & 3.76 & $0.007^{* *}$ \\
Dissatisfaction with current insurance company & 2.96 & 2.66 & $0.048^{*}$ \\
Simplified switching procedures & 3.60 & 3.33 & $0.042^{*}$ \\
Opportunities to switch several times a year & 3.34 & 2.88 & $0.005^{* *}$ \\
\hline
\end{tabular}

${ }^{*}$ significant at $5 \%$; ${ }^{* *}$ significant at $1 \%$. 
For the first group, at least having considered switching their health care insurance, an interesting question remains whether perceived differences indeed are relatively small, or whether differences are in fact large enough, but companies are unable to communicate this effectively. This latter premise would be in line with results from Switzerland [23]. Regardless of the arguments underlying the non-switching behavior, stagnation of the insurance market may result consequently. Whenever consumers have not even considered switching insurance providers, stimulating this group of consumers seems nearly impossible. Consumers that did consider switching their health care insurance simply demand stronger and better communicated differences. If this necessary improvement does not occur, a further decline of the health care insurance market seems to be likely.

\subsection{Results 2010-2011}

As mentioned earlier, our final survey was executed in 2011. This was a relatively small survey, explicitly questioning why Dutch consumers did not decide to switch their basic or supplementary insurance. One of the issues mentioned by Roos and Schut [2] was that consumers in the Netherlands were afraid of not being accepted for the supplementary policy. This issue is particularly important, because 60 percent of our survey respondents believe that the basic and supplementary insurance are interconnected. Our results show that 41 percent of our respondents is afraid of not being accepted when applying for a new supplementary insurance. Moreover, this survey also shows that these highly educated people have difficulties finding the right alternatives. 64 percent of the respondents states not being able to find a good alternative insurance product and 72 percent of the respondents mentions having difficulties understanding the insurance market. However, also the seemingly indifference remains important. 78 percent of the respondents is unwilling to change each year, whereas 81 percent thinks switching is useless because the differences are too small (results not in table).

\section{CONCLUSIONS}

Our research complied with the Helsinki Declaration if applicable. According to the Dutch "Medical Research involving human subjects Act”, our study did not require ethics approval by a medical ethics committee.

The Netherlands introduced the new Health Insurance Act (HIA) in 2006, combining mandatory basic insurance for each citizen with an opportunity to voluntarily buy a supplementary insurance. The reason was that health care costs had risen sharply and this system contributes to more market-orientation. The basic insurance packages are comparable, and there is a mandatory ac- ceptance by insurance providers, whereas there is no obligatory acceptance for supplementary insurance, and insurance companies may even require medical underwriting [2].

Within the HIA, Dutch consumers are allowed to switch their health plan once a year, and this behavior was thought to stimulate insurance companies competing on price and quality. For basic insurance, insurance companies could have competed on price only. However, and despite formal law requirements stressing that the basic insurance and supplementary insurance should be treated separately, 60 percent of our survey respondents believe both insurance products are interconnected. As such, both quality and price of the entire health insurance product are important.

In 2006, the introduction of the HIA resulted in a mobility of almost 20 percent among Dutch consumers nation wide. The results from the 2005-2006 survey show that the most important factors to change health insurance were monthly premium and membership of a purchasing group, whereas company service and dissatisfaction towards the insurance company were less important. During the following years, however, the percentage of consumers switching their health plan decreased to four to five percent. Furthermore, many mergers and acquisitions occurred, resulting in four big players covering the market. The 2008-2009 survey therefore also gained insights into why consumers do not change their insurance policy. Firstly, consumers perceived too limited monthly premium differences. Secondly, they were satisfied with the service of the current insurance provider and perceive the current state as being convenient, not adjusting their insurance package. And finally, if they actively searched for information, they perceived the information as being too complex or difficult to compare, resulting in nonswitching behavior.

These results were confirmed in the 2010-2011 survey. In addition, one of the issues mentioned by Roos and Schut [2] was that consumers in the Netherlands were afraid of not being accepted for the supplementary policy. This issue is particularly important, because consumers also believe the basic and supplementary insurance are interconnected. Our results show that 41 percent of our respondents are afraid of not being accepted when applying for a new supplementary insurance. Moreover, this survey also shows that these highly educated people have difficulties finding the right alternatives. But the larger proportion of the Dutch consumers simply seems indifferent to change opportunities; they believe switching is useless because the differences are too small.

Stagnation of the insurance market may result. Whenever consumers have not even considered switching insurance providers, stimulating this group of consumers seems relatively ineffective, which seems contradictory 
to the initial idea of managed competition with rational consumers. Consumers that did consider switching their health care insurance demand stronger and better communicated differences. With only four big players one could question whether insurance companies have a sufficient incentive to compete with each other.

\section{Future Developments}

What could be effective strategies of the Dutch government to increase switching behavior, increasing market competition among insurance providers? First, and in line with Roos and Schut [2], the government could remove the links between basic and supplementary insurance packages. Since there is a mandatory acceptance for basic insurance, this would stimulate consumers to consider switching their basic insurance alone. Second, the Dutch government could re-introduce a mandatory acceptance for the supplementary insurance. Roos and Schut [2] suggest to better communicate underwriting practices and policy acceptance. However, since there seems to be a low rejection rate anyway, the best solution in our view is to have mandatory acceptance for both the basic insurance and supplementary insurance, which would strongly improve the potential mobility of Dutch consumers. Finally, communication could be improved. As our surveys show, even the highly educated people in the Netherlands have problems finding the right information to compare insurance packages. A "virtual guardian angel” model as suggested by Poiesz \& Van Raaij [22] might help consumers in improving their decision making.

This study, naturally, is subject to several limitations. First, our samples are relatively small. Second, our data is biased towards highly educated people. As mentioned before, however, we expect results to be even worse among lower educated people. Finally, there might have been an influence of the global credit crunch, which we did not include in our measurement. It will be interesting to follow the future developments of the insurance market. Furthermore, in-depth exploration is necessary of the possibility of a "virtual guardian angel” model as well as of the effects of a mandatory acceptance for supplementary insurances on switching behavior.

\section{REFERENCES}

[1] Rosenau, P. and Lako C.J. (2008) An experiment with regulated competition and individual mandates for universal health care: The new Dutch health insurance system. Journal of Health Politics, Policy and Law, 33, 1031-1055. doi:10.1215/03616878-2008-033

[2] Roos, A.F., and Schut, F.T. (2012) Spillover effects of supplementary on basic health insurance: Evidence from the Netherlands. European Journal of Health Economics,

\section{3, 51-62. doi:10.1007/s10198-010-0279-6}

[3] Vektis (2009) Verzekerdenmobiliteit en Keuzegedrag 2009. Vektis, Zeist.

[4] Maarse, H. (2011) Markthervorming in de zorg. Maastricht University, Maastricht.

[5] Okma, K.G.H. and Crivelli, L. (2010) Six countries, six reform models: The healthcare reform experience of Israel, The Netherlands, New Zealand, Singapore, Switzerland and Taiwan: Healthcare reforms "under the radar screen”. World Scientific Publishing, Hackensack.

[6] Balogh, R. and van Veen-Dirks, P. (2010) Marktwerking in de zorg: Budgettering in roerige tijden. Maanblad voor Accountancy en Bedrijfseconomie, 10, 493-505.

[7] Hendriks, M., de Jong, J., van Brink-Muinen, A. and Groenewegen, P. (2010) The intention to switch health insurer and actual switching behaviour: Are there differences between groups of people? Health Expectations, 13, 195-207. doi:10.1111/j.1369-7625.2009.00583.x

[8] Buchmueller, T.C. and Feldstein, P.J. (1997) The effect of price on switching among health plans. Journal of Health Economics, 16, 231-247. doi:10.1016/S0167-6296(96)00531-0

[9] Van Beest, F., Lako, C., Vyrastekova J. and Sent E.M. (2008) Veranderen van zorgverzekeraar. Economisch Statistische Berichten, 93, 518-521

[10] Van de Ven, W.P.M.M. and Schut, F.T. (2009) Managed competition in the Netherlands: Still work-in-progress. Health Economics, 18, 253-255. doi:10.1002/hec.1446

[11] Ng, J., Kasper, J., Forrest, C. and Bierman, A. (2007) Predictors of voluntary disenrollment from medicare managed care. Medical Care, 45, 513-520. doi:10.1097/MLR.0b013e31802f91a5

[12] Risker, C. (2000) Factors influencing employee health plan choice in the corporate Setting. Health Marketing Quarterly, 18, 15-27. doi:10.1300/J026v18n01_02

[13] Anderson, C. (2003) The psychology of doing nothing: Forms of decision avoidance result from reason and emotion. Psychological Bulletin, 129, 139-166. doi:10.1037/0033-2909.129.1.139

[14] Dormont, B., Geoffard, P.-Y., Lamiraud, K. (2009) The influence of supplementary health insurance on switching behaviour: Evidence from Swiss data. Health Economics, 18, 1339-1356. doi:10.1002/hec.1441

[15] Beaulieu, N.D. (2002) Quality information and consumer health plan choices. Health Economics, 21, 43-63. doi:10.1016/S0167-6296(01)00126-6

[16] Schwartz, B. (2004) De paradox van keuzes: Hoe teveel een probleem kan zijn. Spectrum,

[17] Abraham, J. M., Feldman R., Carlin C., and Christianson J. (2006) The effect of quality information on consumer health plan switching: Evidence from the buyers health care action group. Journal of Health Economics, 25, 762781. doi:10.1016/j.jhealeco.2005.11.004

[18] Hurenkamp, M. and Kremer M. (2005) Vrijheid verplicht. Over tevredenheid en de grenzen van keuzevrijheid. Van Gennep, Amsterdam.

[19] Kerssens, J.J., Delnoij, D.M.J., Verweij, J.A. and van der 
Schee, E. (2002) De keuze van ziekenfondsverzekerden voor een zorgverzekeraar. TSG Gezondheidswetenschappen, 80, 35-42.

[20] CBS. 14 april (2008) Web Magazine.

[21] Atos Consulting (2007) Mobiliteit in zorgverzekeringsmarkt neemt sterk af. Atos Consulting, Utrecht.

[22] Poiesz, T. and van Raaij, W.F. (2008) Strategic marketing and the future of consumer behaviour: Introducing the virtual guardian angel. Edward Elgar, Cheltenham.

[23] Rosenau, P. and Lako, C.J. (2008) Health insurance experiments in the Netherlands and Switzerland: A rejoinder with updates. Journal of Health Politics, Policy and Law, 33, 1073-1077. doi:10.1215/03616878-2008-037 